\title{
Fisher information exponential dispersion family and applications
}

\section{ION MIHOC and CRISTINA-IOANA FĂTU}

\begin{abstract}
.
In this article we discuss some aspects of the Fisher information, under certain regularity conditions, then we have in view a very important exponential family, namely, the exponential dispersion family. Also, we study some implications of this last family in the case of the univaried generalized linear models.
\end{abstract}

\section{REFERENCES}

[1] Jorgensen, B., The theory of Dispersion Models, (1997), London: Champan \& Hall

[2] Landsman, Z. and Makov, U., Exponential dispersion models and credibility, Scand. Actuar. J., 1998, No. 1, 89-96

[3] Mihoc, I. and Fătu, C. I., About some properties of the Fisher information in the sample theory, Automat. Comput. Appl. Math., ISSN 1221-437X, 19 (2010), No. 2, 97-108

[4] Nedler, J. A. and Wedderburn, R. W. M., Generalized linear models, J. Roy. Statist. Soc. Ser. A, 135 (1972), 370-384

[5] Renshaw, A. E. and Haberman, S., Generalized linear models and actuarial science, The Statistician, 1996, No. $45,41-65$

FACULTY OF ECONOMICS

CHRISTIAN UNIVERSITY "DiMITRIE CANTEMIR"

T. Mihali 56, Cluj-NaPOCA, Romania

E-mail address: ion.mihoc@cantemircluj.ro

E-mail address: cristina.fatuecantemircluj.ro

Received: 30.11.2011; In revised form: 10.05.2012; Accepted: 30.06.2012

2010 Mathematics Subject Classification. 62B10, 62H10, 62J12.

Key words and phrases. Statistical estimation, score function, Fisher information, exponential dispersion family, generalized linear models.

Corresponding author: Ion Mihoc; ion.mihoc@cantemircluj.ro 